\title{
Knowledge on HIV Prevention Measures Among Male Learners in Secondary Schools in Oshana Region, Namibia
}

\author{
Peneyambeko Ipawa Shikulo ${ }^{1}$, Louise Pretorius ${ }^{2}$, Ndapeua Shifiona ${ }^{2} \&$ Daniel Opotamutale Ashipala $^{2}$ \\ ${ }^{1}$ School of Public Health, Faculty of Health Sciences, University of Namibia (UNAM), Windhoek, Namibia \\ ${ }^{2}$ School of Nursing, Faculty of Health Sciences, University of Namibia (UNAM), Windhoek, Namibia \\ Correspondence: Mrs Ipawa Peneyambeko Shikulo, Ministry of Health and Social Services, Oshana Regional \\ Health Directorate, Private Bag 5501 Oshakati, Oshakati East, Namibia. Tel: 065-221-379. E-mail: \\ ipawash@gmail.com
}

Received: October 31, 2018 Accepted: February 17, 2019 Online Published: March 29, 2019

doi:10.5539/gjhs.v11n5p10 URL: https://doi.org/10.5539/gjhs.v11n5p10

\begin{abstract}
Human Immunodeficiency virus (HIV) has continued to pose significant social, economic and developmental challenges worldwide. The purpose of the study was to assess the knowledge on HIV prevention among male learners in secondary schools in Oshana Region. The objectives of the study were to: assess and describe the knowledge of male learners in Secondary Schools in Oshana Region about HIV preventive measures. A quantitative, cross sectional design, based on the self-report of the participants, was utilized to achieve the aim of the study. Findings of this study showed that $95.4 \%$ had knowledge that HIV can be prevented by consistent and correct use of a condom during sexual intercourse. It has become evident that much still need to be done to make HIV prevention among youth more effective.It is hereby recommended that the Ministry of Education takes the lead to educate the learners on HIV preventive and control measures.
\end{abstract}

Keywords: knowledge, adolescent, HIV preventive measures, risky sexual behaviours, male learners

\section{Introduction}

Since its entry into the global public health arena in the eighties, Human Immunodeficiency virus (HIV) has continued to pose significant social, economic and developmental challenges worldwide. Globally, an estimated 36.9 million people were living with HIV in 2017 while the number of new HIV infections in eastern and southern Africa in 2011 were 1.1-1.3 million (UNAIDS, 2017). Heterosexual activities remain the commonest mode of transmission especially in sub-Saharan Africa (NDHS, 2016) Sexual behavior change appears to be the most effective way of curbing further spread of the disease. Sub-Saharan Africa remains the region that is most affected by the HIV epidemic, despite positive signs that HIV prevalence is declining overall among young people in the region (UNAIDS, 2017). The high numbers of new infections among young people in eastern and southern Africa (ESA) remain a serious concern, as is the fact that the majority of adolescents and young people living with HIV are growing up in the same region. Africa remains the most affected region in the world (UNAIDS, 2017).

HIV prevalence in Namibia is among the highest in the world. The first case of HIV in Namibia was recorded in 1986 and since then the prevalence of the disease has been on the increase with occasional decrease in numbers. The Ministry of Health and Social Services (MoHSS) conducts a sentinel zero-survey every two years to monitor the progression of the epidemic in the country. HIV prevalence has risen from $17,8 \%$ in 2008 to 18 , and $2 \%$ in 2012. The HIV prevalence for 2014 was $16.9 \%$, which indicates a slight decline, while in 2016 is $17.2 \%$. There is still a high rate of infection among the youth (MoHSS, 2016). The trend in HIV prevalence among young people is a better indication of recent trends in HIV incidence and risk behaviour (UNAIDS, 2017). The National Demographic and Health Survey (NDHS) conducted in the year 2016 in Namibia indicated that the age at which young people first have sex is from thirteen years, implying that young people have sex before the age of 15 . This is considered premarital sexual activity and it increases young people's potential exposure to HIV (UNAIDS, 2017).

Adolescents and young people represent the future of every society According to Kar, Choudhury \& Singh (2015) documented that secondary school learners are in the adolescent age, which is the time that they begin to take interest in sexual relationships. It has concluded that youths are at a stage when they may want to experiment with 
sex without giving much consideration to the implications of their present behaviour. Therefore, better education and public health measures can be hugely beneficial to their health and development. The main goal of the afore-mentioned is to delay the age at which young people first have sex and discourage premarital sexual activity as this will reduce their potential exposure to HIV.

MoHSS (2016) National HIV Sentinel survey reported that there was an increase in HIV prevalence among the youth (15-24 years) in Oshana Region from 8.3\% in 2008 to $14.8 \%$ in 2010. The 2014 HIV Sentinel survey indicated an increase in HIV prevalence in the same age group from $7.8 \%$ in 2012 to $9.4 \%$ in 2014 while in 2016 is $9.0 \%$ (MoHSS, 2016). This age group comprises those who are in secondary schools and at the post-secondary levels. They constitute part of the active and vibrant members of the community and generally it is known that men play a key role as gate-keepers in the community. The high prevalence of HIV infection among this active and vibrant member of the population may in part be attributed to lack of adequate information that would engender behaviour change.

This study was therefore undertaken to fill the knowledge gap on the subject matter and further arm health educators, peer counselors, and other stakeholders with the necessary information to address the information needs on HIV. Increasing knowledge of HIV can be a powerful means of fostering positive attitudes and building safe practices among youth. Hence, a clear understanding about knowledge among any population is very important for planning to control or prevent the spread of HIV (Pharr, Enejoh, Mavegam, Olutola, \& Karick, 2017). Although HIV related KAPs are reported in studies from other countries, there was no such information for male learners in secondary school in Oshana region. Therefore, this study was conducted among male learners in Secondary School in Oshana region to determine their level of knowledge toward HIV preventive measures.

\section{Goals and Objectives}

The goal of the study was to assess and describe the knowledge on HIV prevention among male learners in secondary schools in Oshana Region. Its objectives were to assess the knowledge about HIV preventive measures among male learners in Secondary Schools in Oshana Region.

\section{Research Design and Methods}

\subsection{Design}

A cross-sectional quantitative design utilizing a descriptive design was conducted. This study employed a quantitative approach as a preferably, efficient and inexpensive method in collecting data from a large number of respondents in a survey (Brink, van Rensburg, \& van der Walt, 2018)

\subsection{Study Population}

The study population for this study comprised of all male learners in four selected senior secondary schools in Oshana region, Namibia.

\subsection{Inclusion and Exclusion Criteria}

All learners who were randomly selected from the list, who were 18 years old by then and whose parents/guardians consented to the study and were willing to participate in the study were included in the study. Learners under the age of 18 years without permission from their parents/guardians to participate in the study were excluded from the study.

\subsection{Sampling and Sample Size}

Participants were randomly selected from the selected secondary school list of 1429 male learners. Simple random sampling technique was used and every second or third officer on the list was selected for participation. A total numbers of 592of male learners were selected. A total number of (731) data collection instruments were prepared and circulated to all selected Secondary Schoolwithin the region.

\subsection{Data Collection Tool}

In this study, data was collected using questionnairesas primary source of data collection. This data collection method was used for the study, as it is considered to be a relevant tool to use when the researcher seeks to collect data from larger sample (Brink at el, 2018).

\subsection{Data Collection Methods}

The researcher distributed 731 questionnaires to participants and a total number of 592 (80\%) questionnaires were completed and returned. 


\subsection{Data Analysis}

Data analysis from the questionnaires was presented as descriptive statistics and evaluated with quantitative, computerised statistical techniques, using SPSS version 24.

\section{Ethical Considerations}

HIV is considered as sensitive issues due to the nature of the stigma and discrimination surrounding the disease. Participants in this study were assured confidentiality and anonymity. They were not obliged to divulge their names or personal particulars expect their gender, age and educational background. Participation in the study was voluntary and informed consent form was considered prior participation. Participation in the study was voluntary and participants were informed that they could withdraw at any stage. Participants were assured that research material and all documents with their response are going to be kept safe in an area only accessible to the researcher. For privacy, schools were study was conducted were coded with letters as school A to school D.

\section{Results}

5.1 Socio Demographic Description of Study Participants

\subsubsection{Age of Participants}

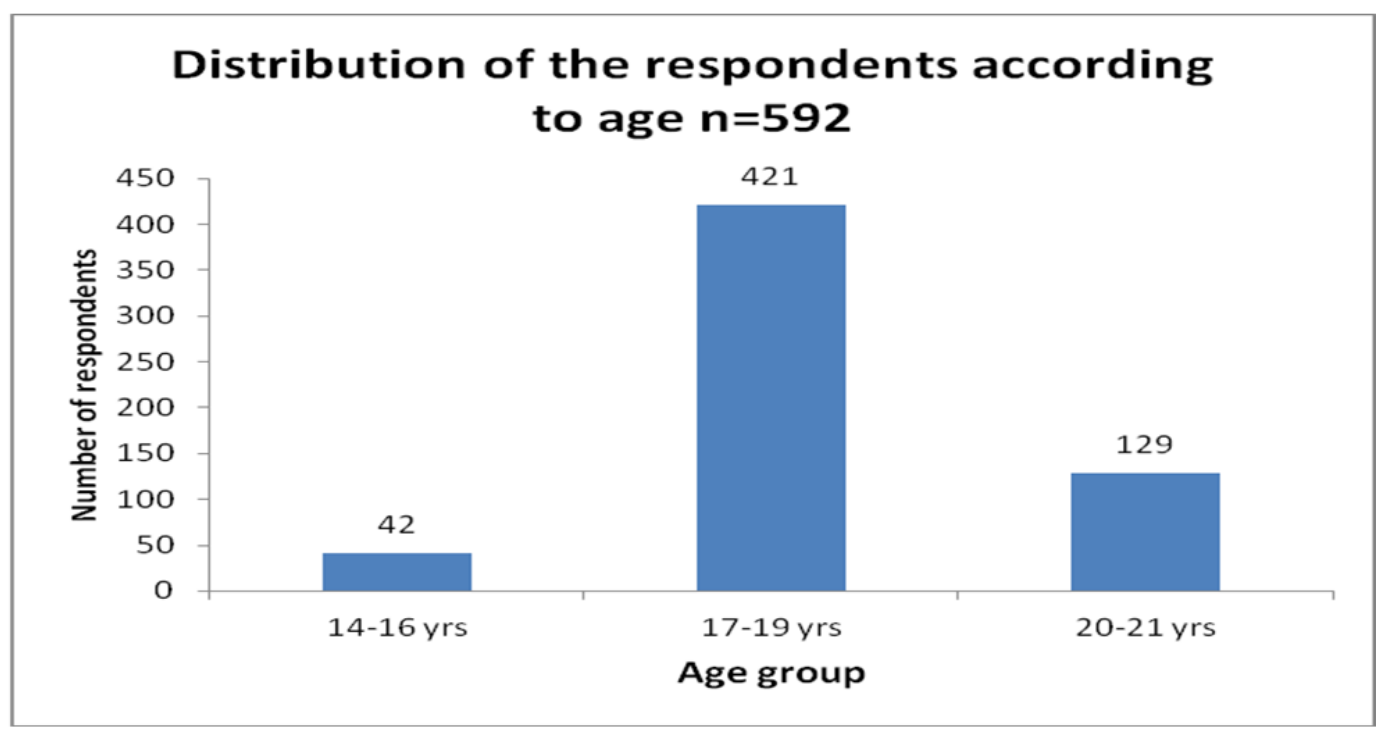

Figure 1. Distribution of respondents according to age

Figure 1 outlines the age of learners who took part in the study. It indicates majority of $421(71.1 \%)$ were $17-19$ years old, followed by age group 20-21 years that were $129(21.8 \%)$. The learners who were 14-16 years old were $42(7.1 \%)$. Respondents of age 14-16 years were very few. This could be because learners of mentioned age had to obtain written consent from their parents or guardians. 


\subsubsection{School Distribution}

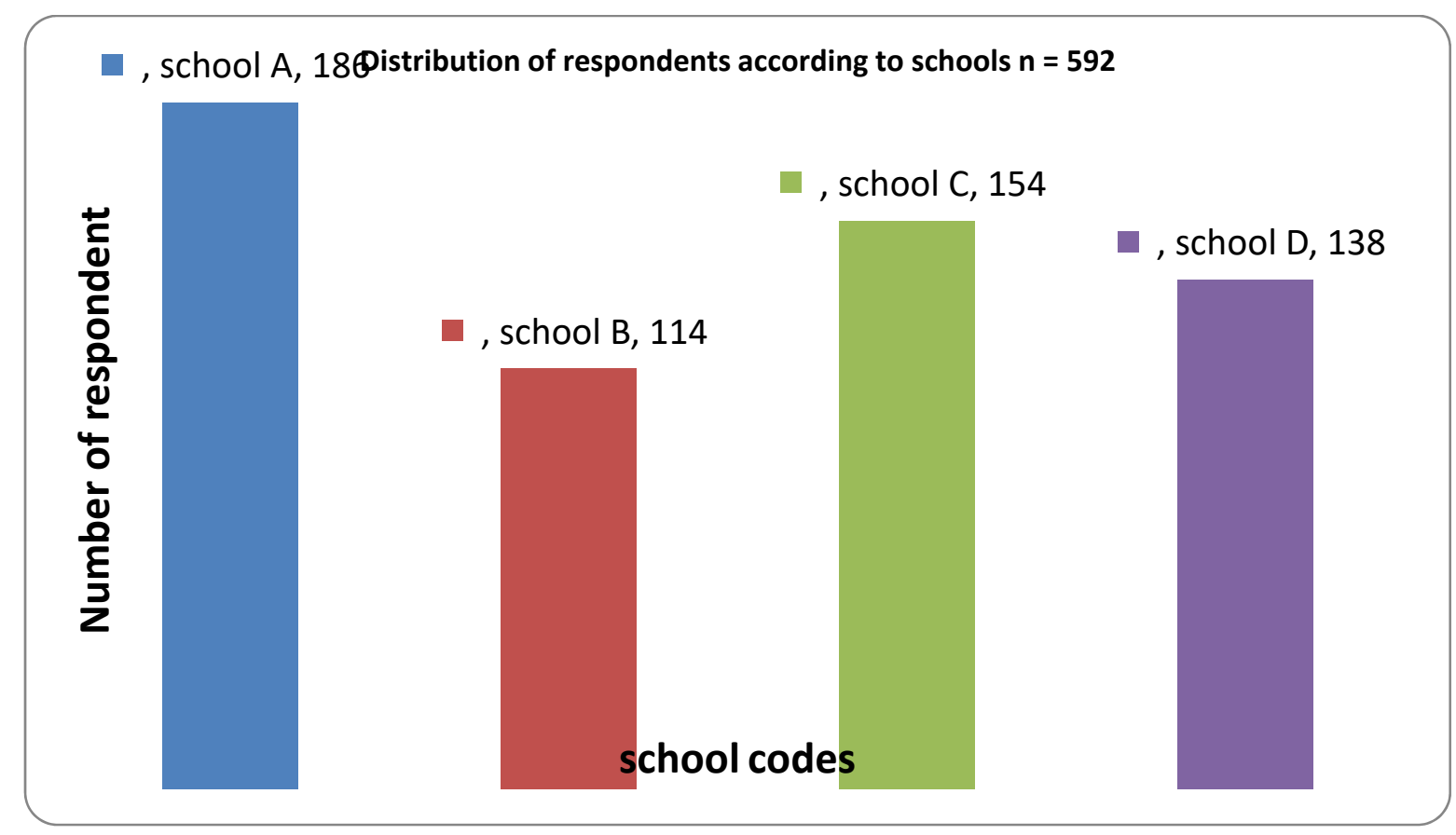

Figure 2. Distributions of respondents according to schools

Figure 2 outlines the distribution of respondents by Schools. A total of 592 respondents participated in the study from all the four schools as indicated in figure 5.2 respectively. The sample comprised of 114 (19.3\%) respondents from School B, $154(26.0 \%)$ from School C and $138(23.3 \%)$ from School D. The largest numbers of respondents of 186 (31.4\%) were from School A.

5.1. 3 Level of Education of Participants

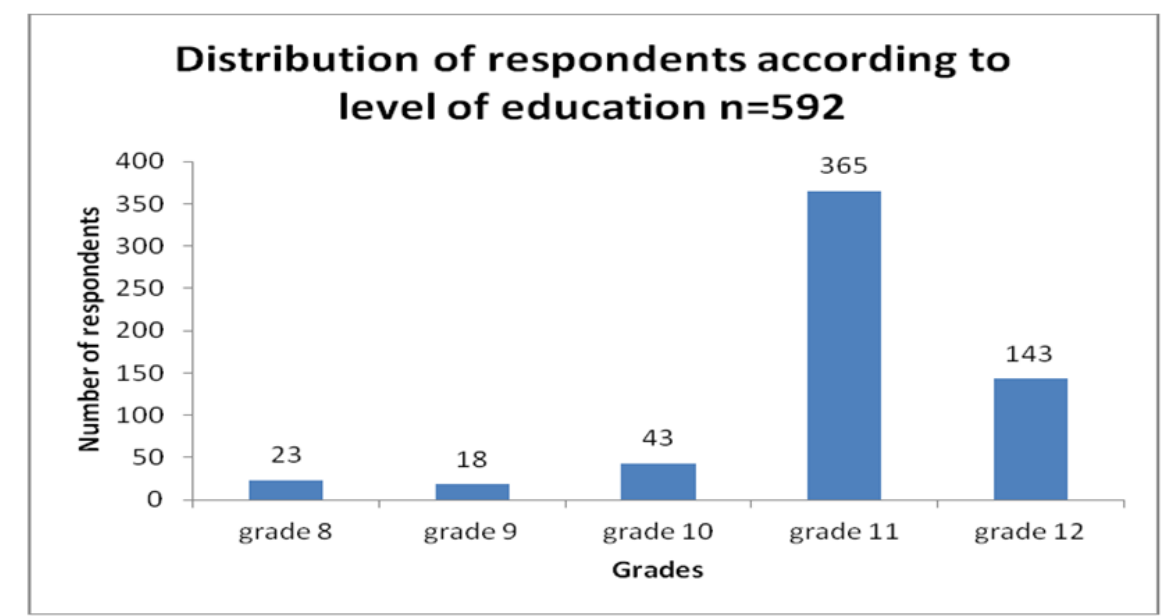

Figure 3. Distribution of respondents according to level of education

Figure 3 outlines the all the grades that were represented in each school. The majority $365(61.7 \%)$ were in grade 11 , followed by grade $12,143(24.2 \%) 43(7.3 \%)$ were in grade 10 , while $23(3.9 \%)$ were in grade 8 and $18(3 \%)$ of respondents were in grade 9. 


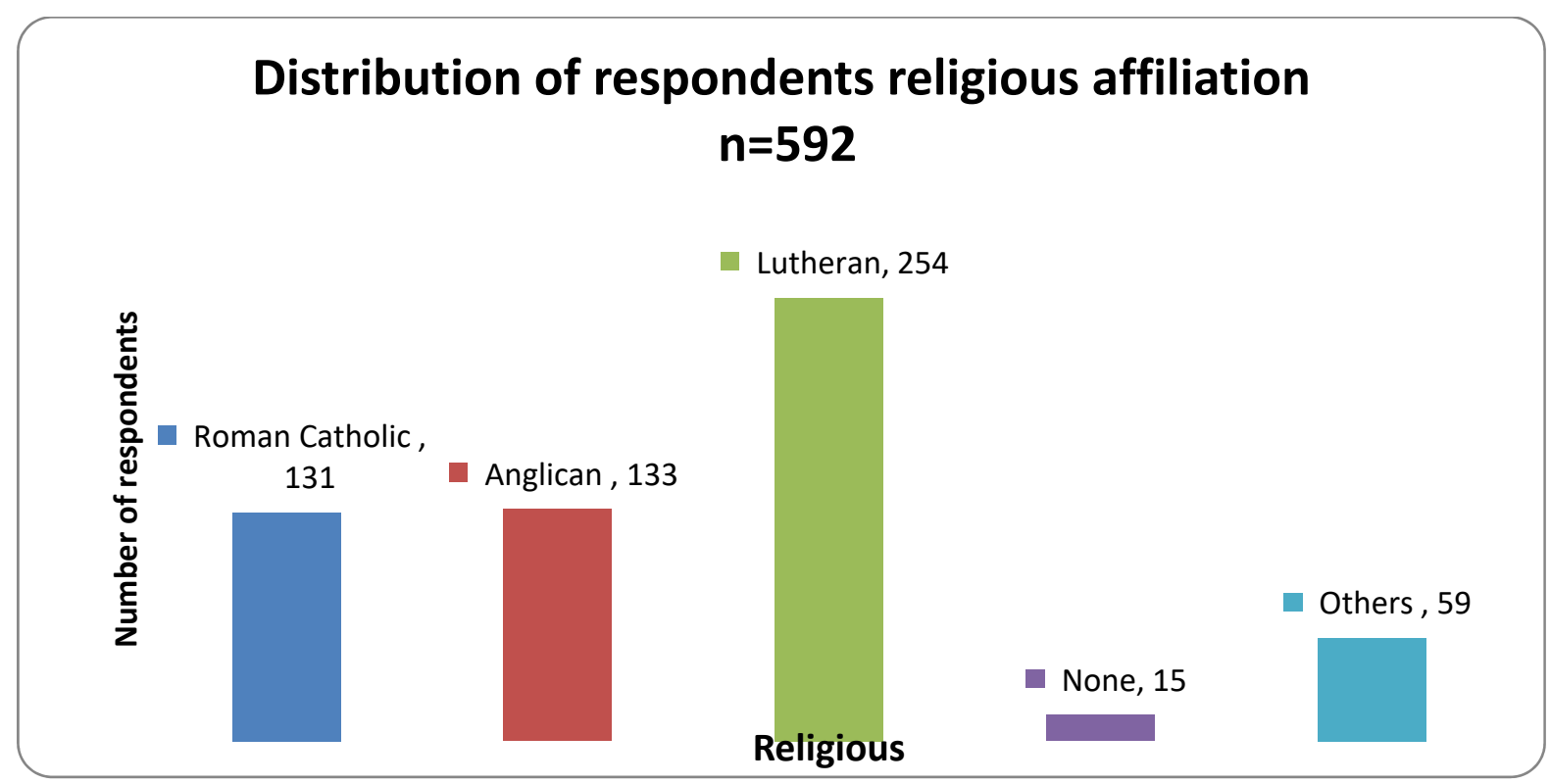

Figure 4. Distribution of respondent's religious affiliation

Figure 4 indicates the religious distribution of respondents in the study. The respondents mainly represented the following four religious groups, whereby majority $43.0 \%$ (254) out of 592 are Lutherans, $22.3 \%$ (132) are Anglicans, $10 \%$ (59) belong to other religious affiliations, namely Four Square, Jehovah Witness, Potters House, Seventh Day Adventist and 2.5\% (15) of the respondents indicated that they did not belong to any religious affiliation.

5.1.5 HIV Prevention Through the Correct Use of Condom During Sex

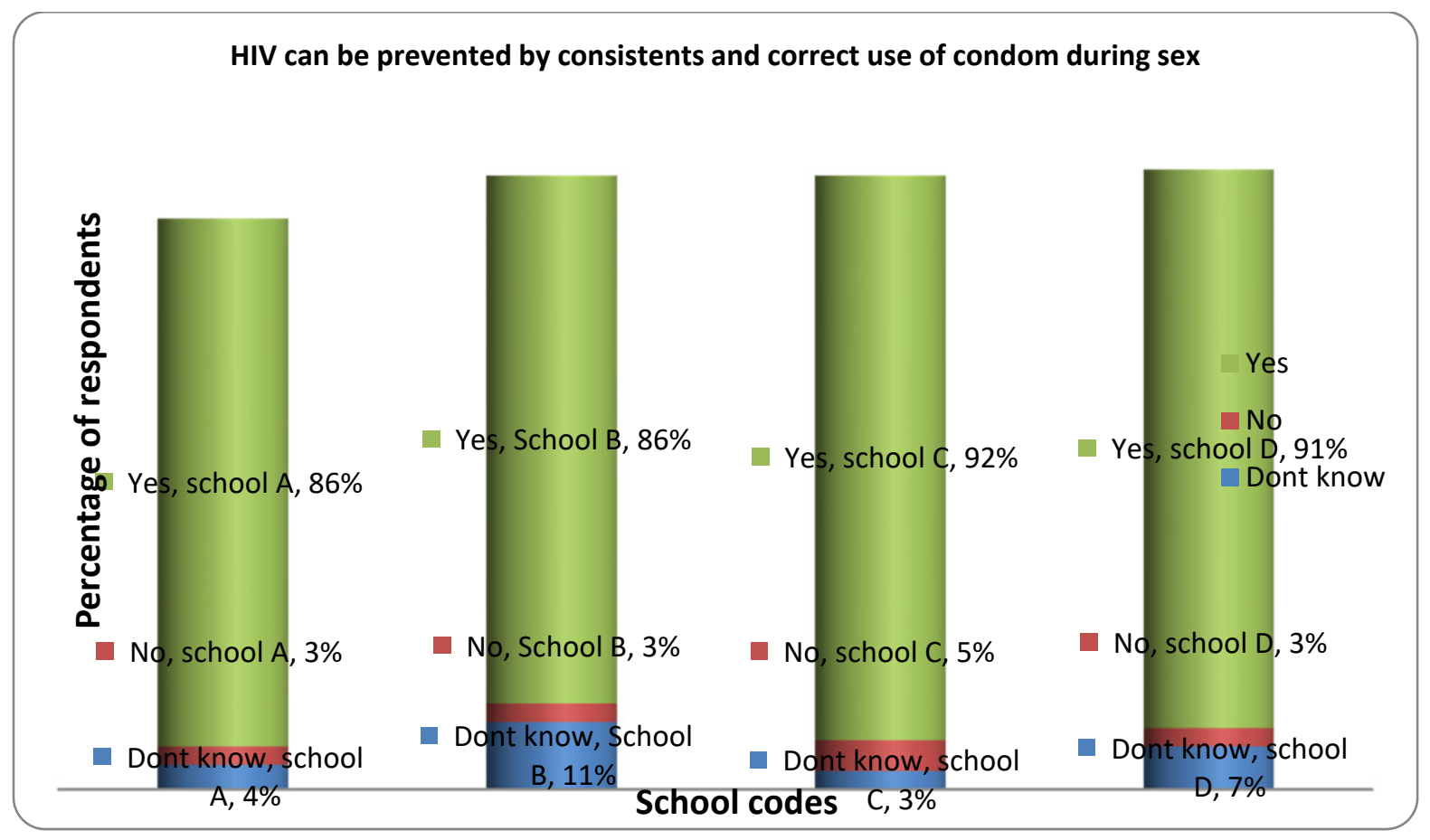

Figure 5. HIV can be prevention by consistency and correct use of condom during sex 
Figure 5 indicates that shows the respondents' knowledge about prevention and control of HIV. Item number ten, indicates a total number of $565(95.4 \%)$ out of 592 respondents had knowledge that HIV can be prevented by consistent and correct use of a condom during sexual intercourse, while $16(2.7 \%)$ out of 592 indicated that that HIV cannot be prevented by consistent and correct use of a condom during sexual intercourse and $11(1.8 \%)$ respondents stated that they did not know if HIV can be prevented by consistent and correct use of a condom during sexual intercourse.

\subsubsection{HIV Prevention by Sticking to One Faithful Single Partner}

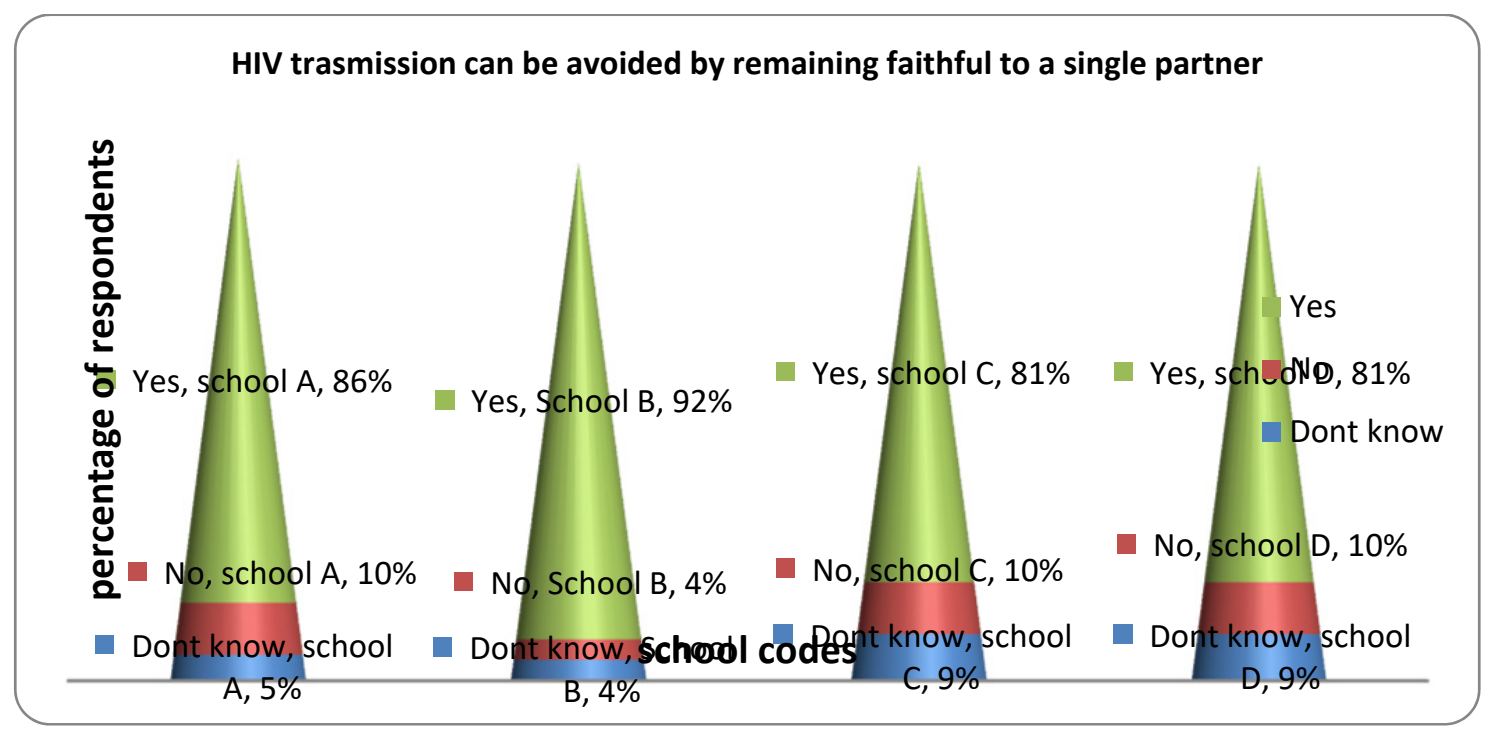

Figure 6 . HIV transmission can be avoided by remaining faithful to a single partner

Figure 6 reveal that majority of participants 501(84.6\%) out of 592 respondents were aware HIV transmissions can be avoided by remaining faithful to a single partner.

\subsubsection{HIV Prevention Before Marriage by a Blood Test}

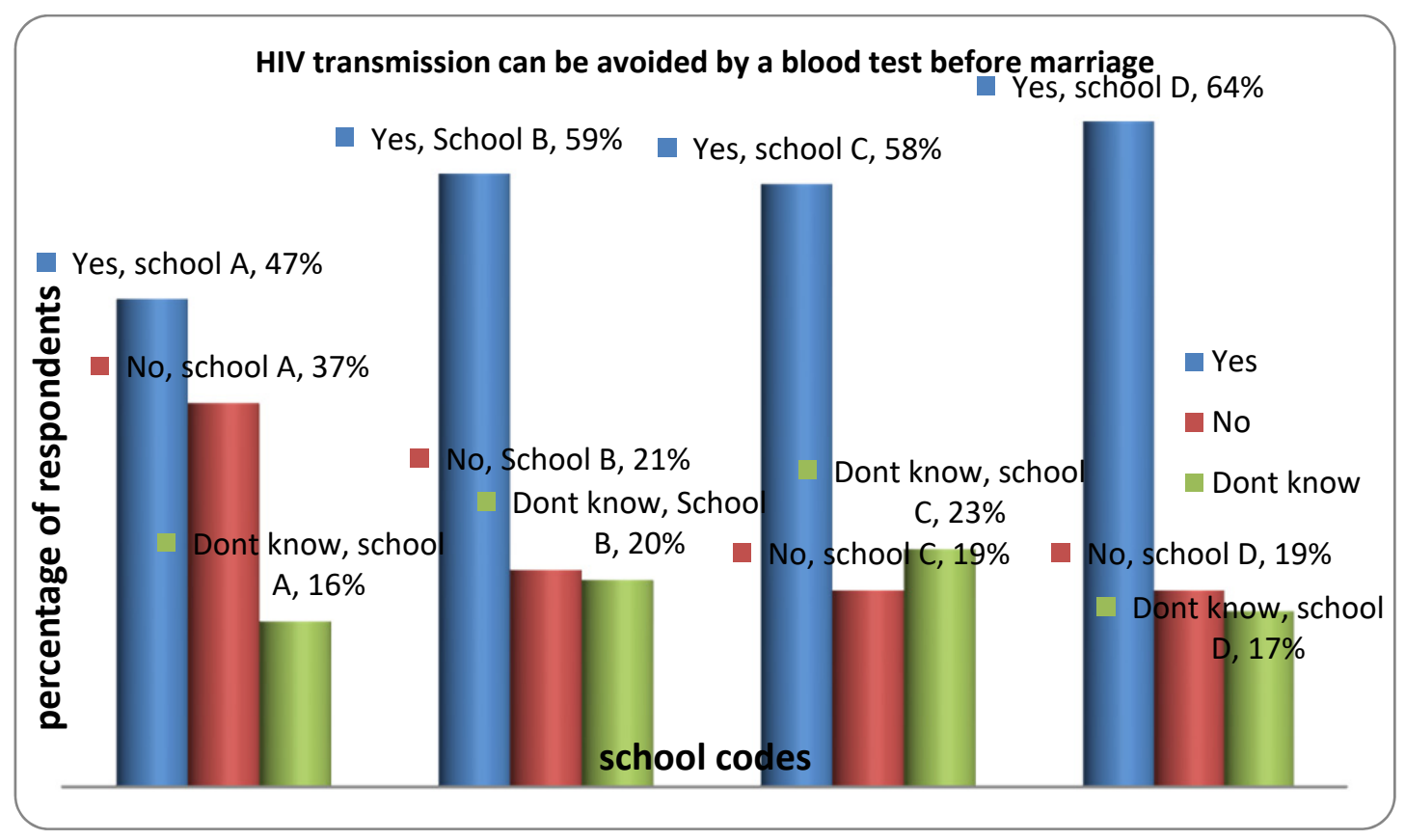

Figure 7. HIV transmission can be avoided by a blood test before marriage 
The study findings indicate the respondents' knowledge about prevention and control of HIV, that HIV infection can be avoided by a blood test before marriage. The study revealed that only $333(56.2 \%)$ out of 592 affirmed that HIV transmission can be avoided by a blood test before marriage, while $112(18.9 \%)$ and 147 (24.8\%) of them indicated that they do not know whether it can be avoided or not respectively.

\subsubsection{HIV Prevention Through Male Circumcision}

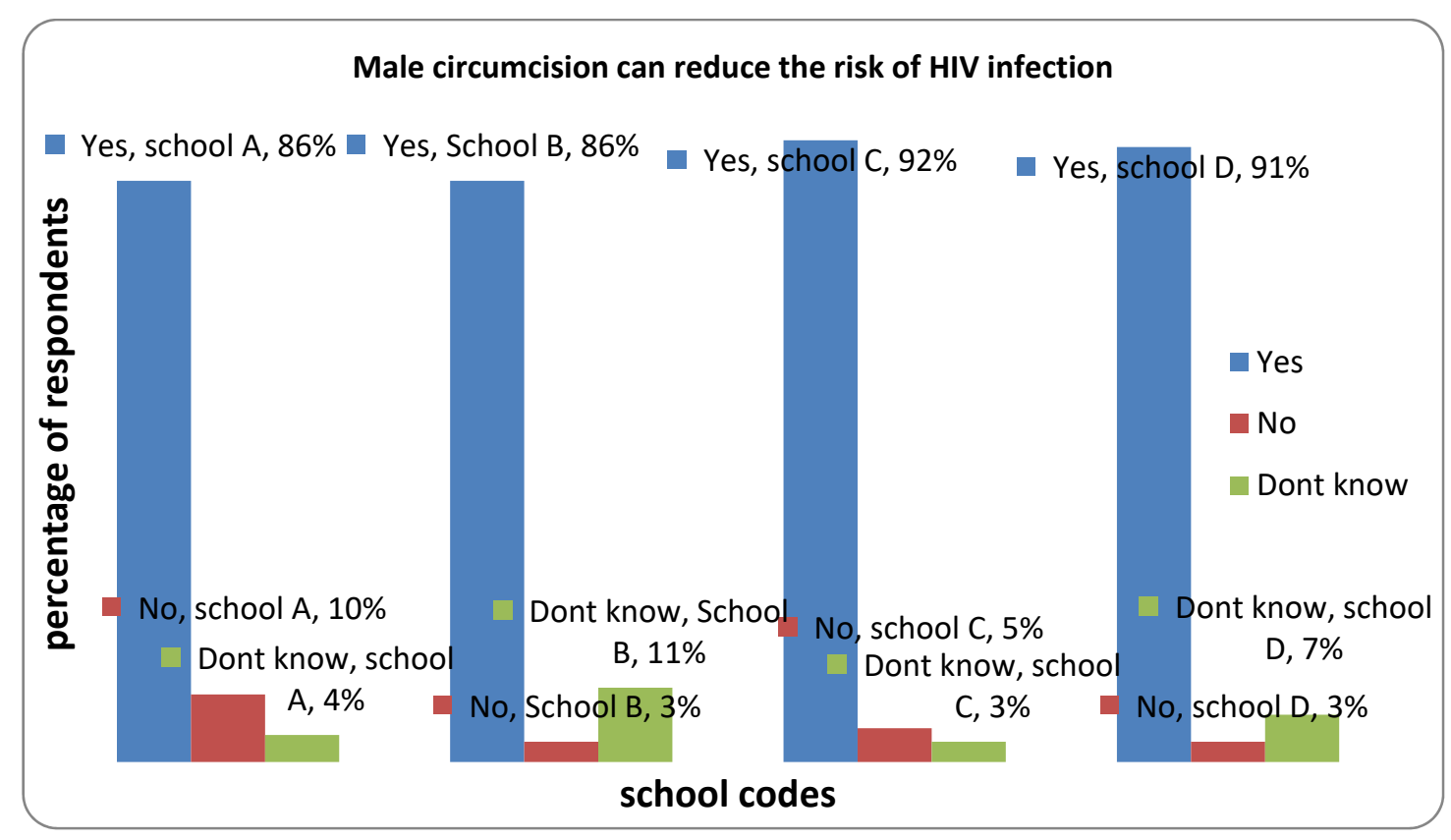

Figure 8. Male circumcision can reduce the risk of HIV infection

The study findings show that majority of $523(88.3 \%)$ out of 592 of the respondents were aware that male circumcision can reduce the risk of HIV infection, while $35(5.9 \%)$ were not aware thereof. Thirty four (5.7\%) of them think that male circumcision cannot reduce the risk of HIV infection at all. 


\subsubsection{HIV Prevention Through Awareness Control Programme in the Region}

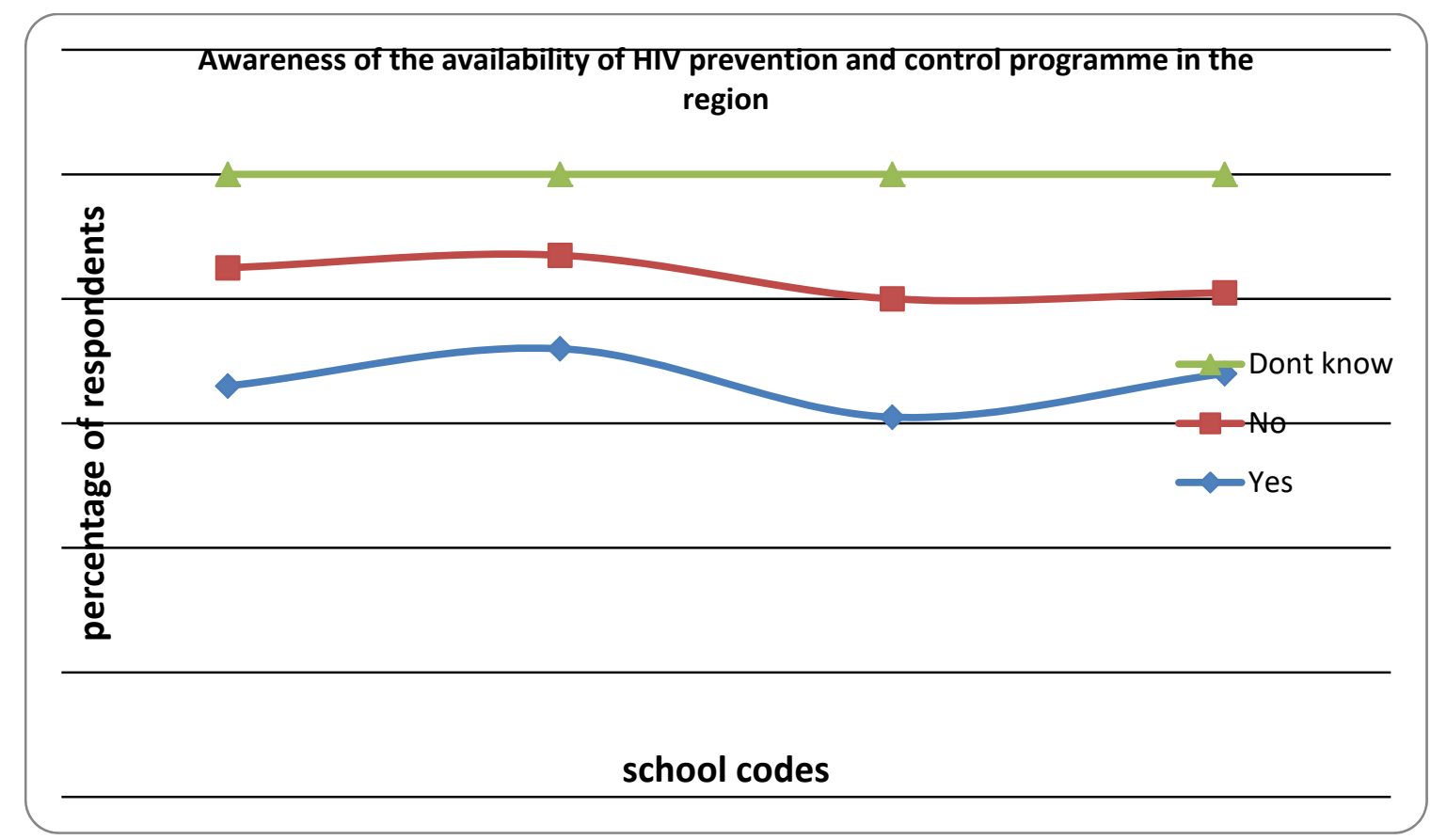

Figure 9. Awareness of the availability of HIV prevention and control programme in the region

The study indicates that majority of $393(66.3 \%)$ out of 592 of the respondents were aware of the availability of HIV prevention and care programmes in the region. One hundred respondents $(16.8 \%)$ of them do not know whether HIV prevention and care programmes are available in the region or not, respectively and $99(16.7 \%)$ of them were not aware at all.

\subsubsection{Effectiveness of Post Exposure Prophylaxis}

\section{Effectiveness of Post Exposure Prophylaxis}

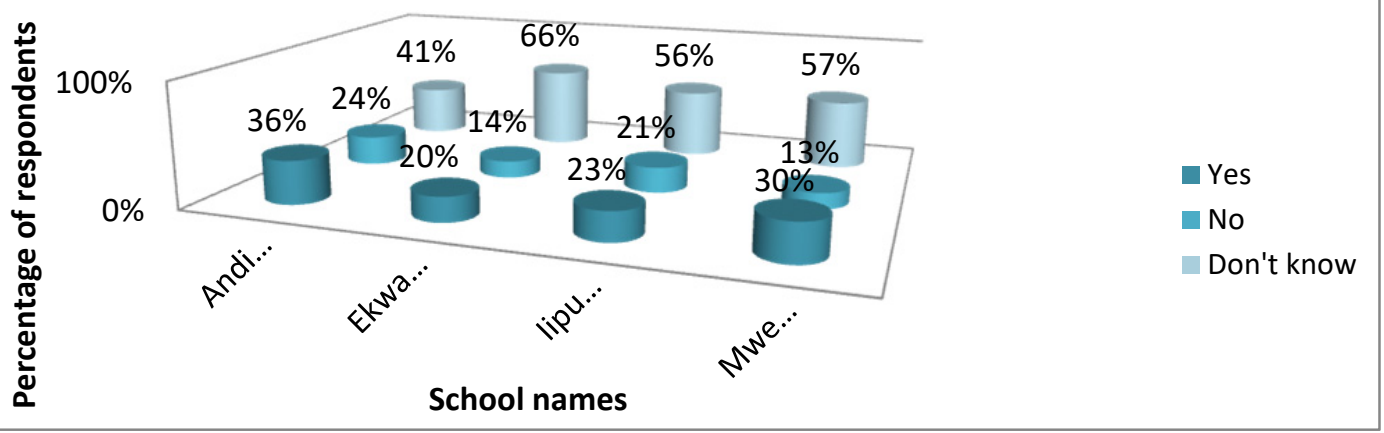

Figure 10. Effectiveness of Post Exposure Prophylaxis

Only few of the respondents 167 (28.2\%) out of 592 were aware that Post Exposure Prophylaxis (PEP) is only effective if the medicine is started within 72 hours of possible exposure to the virus, while more than a half (315) (53.2\%) of the respondents were not aware whether PEP can be effective if it is given within 72 hours or not. Hundred and ten (18.5\%) of them replied "No", indicating that PEP is not effective if it is given within 72 hours of possible exposure to the virus. 


\subsection{Validity and Liability}

The sample size was sufficiently large and was drawn from the large group of the same characteristic to the sample. The questionnaire was pre - tested prior to actual data collection with similar characteristic to the sample. The questionnaire was administered in language understood by both respondents and the researchers. Data quality checks were done in the field as well as before and data processing to ensure completeness and consistency. To address reliability in this study, the same questionnaire was used to collect data from all the participants and this was only done by the researcher alone.

\section{Discussion}

The majority of the respondents were highly knowledgeable about HIV prevention and control with the range between $28.2 \%$ to $95.4 \%$. The most HIV preventive and control measures mentioned were consistent and correct use of a condom, remaining faithful, not sharing needle or syringe and male circumcision. This finding is similar to the findings reported among male high school learners in Cameroon by Nubed \& Akoachele (2016). The findings on HIV prevention and control measures specific to remaining faithful to a single partner and condom use in this study were significantly high at $84.6 \%$ and $95.4 \%$ respectively, compared to $48 \%$ and $69 \%$ reported by (Mkumbo, 2013) in a similar study in Bukoba, rural Tanzania.

The proportion of respondents who were aware that using condom is effective to prevent HIV transmission was high (95.4\%) compared to the study carried out by Macugu, Joash \& Jonathan (2013). In that study, Condom use, awareness and perceptions among Secondary School students in Kenya which showed only $22.9 \%$ of learners thought condoms were effective in protecting against HIV.

This study showed that male circumcision could be one of the HIV prevention measures among youth. A randomized control trial showed that circumcision reduces the risk of HIV infection among heterosexual men by up to $60 \%$. It is expected that this prevention strategy is adopted in many countries that are affected by the epidemic. Namibia is one of the countries that adopted Voluntary Medical Male Circumcision as HIV preventive measures (NDHS, 2016)

It was indicated in this study that condom distribution was among the HIV prevention measures mentioned by the learners. This is also supported by (NDHS, 2016) that increase in condom distribution and use has been a key objective of the National Strategic Framework and both male and female condoms have proved to be effective in preventing HIV, STI and unwanted pregnancy.

It was further documented that getting tested for HIV was one of the HIV prevention measures among youth mentioned by the learners. The Voluntary Counseling and Testing has been identified as an entry point to most HIV and AIDS interventions globally (UNAIDS, 2017) Knowledge of HIV status helps HIV-negative individuals make specific decisions that will help reduce the risk of contracting HIV. For those who are HIV positive, knowledge of their status allows them to take action to protect their sexual partners, to access treatment, and to plan for the future (UNAIDS, 2017) .Therefore, youth should be encouraged to go for voluntary HIV counseling and testing.

Re- introducing of a religious subject in school was one of the effective HIV preventive measures suggested by the respondents. According to social control theories of adolescent behavior, religious functions do encourage adolescents to avoid actions that they might otherwise have taken. It is well known that one of the primary functions of religion is to help people deal with adversity (Arosell \& Carlbom, 2016). Therefore, based on the findings, the respondents' suggestion about the re-introducing of religious education to be a taught subject in schools can be one of the effective HIV prevention measures among youth.

In this study it was found that few learners indicated that HIV can be prevented among youth by avoiding sexual intercourse while under the influence of alcohol.Information on alcohol and drug abuse is important for all adolescents, both regarding its effects on protected sex (for example, forgetting "intentions" to use condoms and a greater risk of incorrect use as well as the potential for HIV infection through sharing unsterilized injecting equipment. Only few learners mentioned peer counselling as one of HIV preventive measures among youth. This finding is similar to the study conducted by (Muswede, 2015) about Perceptions of young adults with regard to condom use in Vhembe district, Limpopo province where it was revealed that respondents seemed to be less comfortable talking about the epidemic with peer educators.

\section{Conclusions}

This study aimed to assess the knowledge toward HIV prevention measures among male learners in Secondary School in Oshana region. A high level of knowledge about prevention was found. Although, the study has found high knowledge about HIV prevention, the HIV prevalence among youth for 2016 is still high $8.5 \%$ looking at 
$17.2 \%$ for Namibia. Therefore, much still need to be done to make HIV prevention among youth more effective.

\subsection{Recommendations}

- The study has found that lack of awareness among learners about the effectiveness of condom used in prevention of HIV and AIDS observed. Therefore, this study recommended that the Ministry of Education to takes the lead to educate the learners on HIV preventive and control measures required because learners should know all methods that they can use to protect themselves from infection.

- Lack of awareness about the availability of HIV prevention and care programme were found by the study. This study recommended MoE -Life skills teachers to mobilize the learners about the availability of HIV prevention and care programmes in school, to strengthen HIV prevention programmes in schools and to make sure that learners are involved from the initial process of planning or designing HIV and AIDS prevention programmes

- The study has found that Learners are less informed about Post-exposure prophylaxis (PEP) and they may not avail themselves to utilize these services if the need arises.

Therefore, this study recommended that MoHSS specific Infection Control Nurse at regional level should take the lead to educate the learners about the Post exposure Prophylaxis guideline so that learners should be aware that if the condom burst during sexual intercourse without knowing one's HIV status they need to visit the hospital within 72 hours.

\subsection{Study Delimitations and Limitation}

The study was delimited to four secondary Schools in one region involving 592 male learners. This limits the generalization of study findings to other regions and to all male learners of the same age. Moreover, and given the sensitive nature of the study, the participants may have given limited information which may have influenced the findings.

\section{Acknowledgements}

Researchers thank all the respondents who took time to participate in this study; without their participation this study would not have been possible. We also thank the Ministry of Education, Arta and Culture for having granted us permission to conduct research in its correctional facility.

\section{Competing Interests Statement}

The authors declare that there are no competing or potential conflicts of interest.

\section{References}

Arosell, J., \& Carbom, A. (2016). Culture and religious beliefs in relation to reproductive health. Best Practice \& $\begin{array}{lllll}\text { Research Clinical Obstetrics \& Gynaecology Journal, } & 32(8), & 77-87\end{array}$ https://doi.org/10.1016/j.bpobgyn.2015.08.011

Brink, H., Van der walt, C., \& Van Rensburg, G. (2018). Fundamentals of Research Methodology for Health Care Professionals (4th ed.) Cape Town: Juta

Kar, S. K., Choudhury, A., \& Singh A. P. (2015). Understanding normal development of adolescent sexuality: A bumpy ride. Journal of Human development sciences, 8(2), 70-74. https://doi.org/10.4103/0974-1208.158594

Ministry of Health and Social Services. (2016). Namibia Demographic and Health Survey 2013 (NDHS). Namibia Statistics Agency. Windhoek: Government of Republic of Namibia.

Ministry of Health and Social Services. (2016). Report of the 2016 National HIV sentinel Survey. MoHSS: Windhoek. Government of Republic of Namibia.

Mkumbo, K. (2013). Assessment of HIV/AIDS knowledge, attitudes and behaviours among students in higher education in Tanzania. Global Public Health, $8(10), \quad 1168-1179$. https://doi.org/10.1080/17441692.2013.837498

Mucugu, P., Joash, M., \& Jonathan, M. (2013) Condom use, awareness and perceptions among Secondary School students in Kenya. International Journal of Asian Social Science, 3(8), 1658-1677 Retrieved from http://www.aessweb.com/journal-detail.php?id=5007

Muswed, J. N. (2015). Perceptions of young adults with regard to condom use in Vhembe district, Limpopo province: South Africa. Retrieved from http://hdl.handle.net/10500/19018 
Nubed, C. K., \& Akoachere, J. T. K. (2016) Knowledge, attitudes and practices regarding HIV/AIDS among senior secondary school students in Fako Division, South West Region, Cameroon. BMC Public Health, 2016, 16(1), 847. 22. https://doi.org/10.1186/s12889-016-3516-9

UNAIDS. (2017). Global AIDS response progress reporting 2017. UNAIDS: New York.

Pharr, J., Enejoh, V. O., Mavegam, B., Olutola, A., \& Karick, H. (2017). A Cross-Sectional Study of the Role of HIV/AIDS Knowledge in Risky Sexual Behaviors of Adolescents in Nigeria. International Journal High Risk Behaviour Addict, 6(4), e63203. https://doi.org/10.5812/ijhrba.63203

\section{Copyrights}

Copyright for this article is retained by the author(s), with first publication rights granted to the journal.

This is an open-access article distributed under the terms and conditions of the Creative Commons Attribution license (http://creativecommons.org/licenses/by/4.0/). 